\title{
APPLICATION OF NEURAL NETWORK SIMULATION SYSTEM TO ELECTRICAL INSULATION DIAGNOSIS OF DISTRIBUTION LINE INSULATORS
}

$\begin{array}{lll}\text { Member } & \text { Yukio Mizuno } & \text { (Nagoya Institute of Technology) } \\ \text { Non-member } & \text { Oscar F. Vanegas C. } & \text { (Nagoya Institute of Technology) } \\ \text { Member } & \text { Katsuhiko Naito } & \text { (Nagoya Institute of Technology) } \\ \text { Non-member } & \text { Tsutomu Sugiyama } & \text { ( NGK Insulators, Ltd.) } \\ \text { Member } & \text { Susumu Ito } & \text { ( NGK Insulators, Ltd.) }\end{array}$

Leakage current of distribution line insulators under various environments were examined in laboratory. A neural network simulation system was constructed for the electrical insulation diagnosis of distribution line insulators referring to waveforms of the leakage current. It is found that the system constructed can distinguish cracked insulators from sound ones.

Key words: Electrical insulation diagnosis, Neural network, Distribution line insulator, Leakage current waveform

\section{Introduction}

Development of electrical insulation diagnosis of power distribution equipment in service is seriously desired. Especially it is so in the case of the distribution equipment since it is directly connected to the final consumers and even a shorttime service interruption is to be avoided by all means. In the case of distribution line insulators, at present, when a small leakage current is detected, many maintenance people will work in order to find out the deteriorated unit as soon as possible. However, tremendous labor, time and cost are required for such a work because of the many scattered equipment in a system.

Several study reports have been published already on the electrical insulation diagnosis of EHV gas-insulated power apparatus ${ }^{(1)}$ by using the neural network simulation system. For distribution equipment, too, similar technique may be applied, but there seems to be many things left undone.

In this paper, as the first step of the study in the electrical insulation diagnosis of the distribution equipment, the distribution line insulator is taken up. A neural network simulation system was constructed for the insulation diagnosis of distribu- tion line insulators referring to waveforms of the leakage current along the surface of or through insulators.

\section{Detection methods of deteriorated line insu- lators}

Several detection methods have been studied in order to find out deteriorated line insulators ${ }^{(2),(3)}$, which are summarized in Table 1. For transmission line insulators, four detection methods have been considered to be effective in finding a deteriorated unit insulator in a string. Values to be measured are reflection signal of LASER shot, voltage allotment in a string, DC resistance and temperature rise compared with other units in a string.

In the case of distribution line insulators, however, since only one insulator is usually used at one spot, detection methods measuring voltage allotment, DC resistance and temperature rise are not applicable. The possible detection methods are to measure reflection signal of LASER shot and to obtain leakage current. The former method is very expensive. Thus, insulation diagnosis by leakage current is examined here. 
Table 1 Detection methods of deteriorated line insulators

\begin{tabular}{|l|l|c|c|c|}
\hline Category & \multicolumn{1}{|c|}{ Values to be measured } & $\begin{array}{c}\text { Transmission } \\
\text { line insulator }\end{array}$ & $\begin{array}{c}\text { Distribution } \\
\text { line insulator }\end{array}$ & Ref.\# \\
\hline \multirow{3}{*}{ Mechanical } & Reflection signal (LASER shot) & $\bigcirc$ & $\triangle$ & $(2)$ \\
\cline { 2 - 5 } & Ultrasonic acoustic noise & $\times$ & $\times$ & $(2)$ \\
\hline \multirow{5}{*}{ Electrical } & Leakage current & $\times$ & $?$ & $(3)$ \\
\cline { 2 - 5 } & Voltage allotment & $\triangle$ & $\times$ & $(3)$ \\
\cline { 2 - 5 } & DC resistance & $\times$ & $\times$ & $(3)$ \\
\cline { 2 - 5 } & Noise (LF,MF,HF,VHF,UHF) & $\triangle$ & $\times$ & $(3)$ \\
\hline Thermal & Temperature rise & $\triangle$ & $\times$ & $(3)$ \\
\hline
\end{tabular}

\section{Measurement of Leakage Current of Distri- bution Insulators}

\subsection{Experimental Procedure}

Pin type and strain (cap-and-pin) type insulators were used. Shape, size and technical particulars of the insulators are shown in Fig. 1 and Table 2.

Leakage current measurement was performed in a laboratory by using the circuit shown in Fig. 2 . Sound insulators and those with an artificially produced crack in their head were prepared and were subjected to various artificial conditions as shown in Table 3.

\subsection{Results}

Some examples of leakage current waveforms obtained are shown in Fig.3. Leakage current along the surface of and through the sound and damaged insulators show significantly different patterns under various working conditions. Special features of the leakage current were as follows:

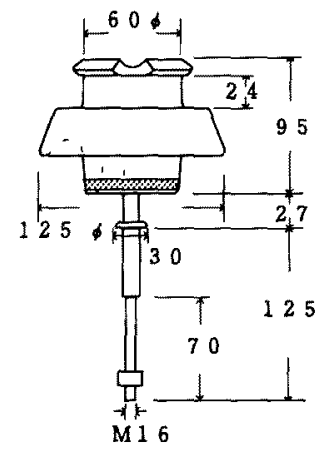

Pin type

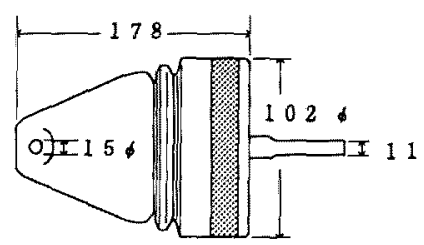

Fig.1 Shape and Dimensions of specimens.
Table 2 Technical particulars of specimens.

\begin{tabular}{|l|r|r|}
\hline \multicolumn{1}{|c|}{ Items } & $\begin{array}{r}\text { Pin } \\
\text { type }\end{array}$ & $\begin{array}{c}\text { train } \\
\text { type }\end{array}$ \\
\hline $\begin{array}{l}\text { Power frequency wet withstand } \\
\text { voltage, } \mathrm{kV}\end{array}$ & 22 & 24 \\
\hline $\begin{array}{l}\text { Lightning impulse withstand } \\
\text { voltage, } \mathrm{kV}\end{array}$ & 65 & 75 \\
\hline $\begin{array}{l}\text { Lightning impulse flashover } \\
\text { voltage, } \mathrm{kV}\end{array}$ & 80 & 90 \\
\hline $\begin{array}{l}\text { Power frequency puncture } \\
\text { voltage, } \mathrm{kV}\end{array}$ & 90 & 100 \\
\hline Mechanical breaking load, kgf & 200 & 4000 \\
\hline Surface leakage distance, $\mathrm{mm}$ & 140 & 205 \\
\hline Surface area, $\mathrm{cm}^{2}$ & 355 & 480 \\
\hline Weight, kg & 1.4 & 2.0 \\
\hline
\end{tabular}

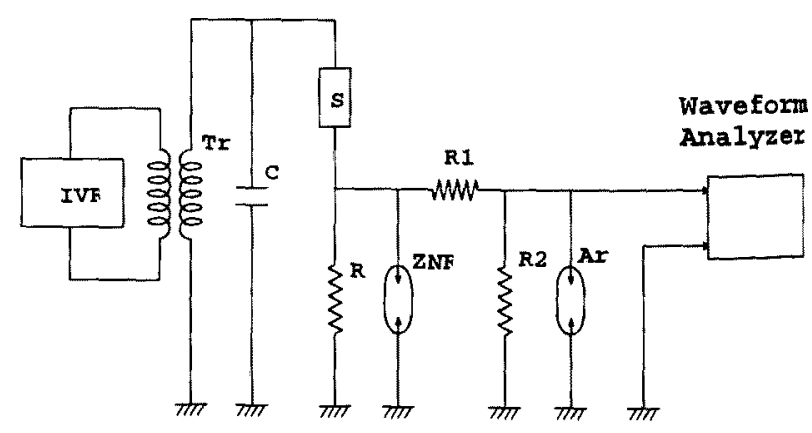

IVR:Induction voltage regulator Tr: Testing transformer

$\mathrm{C}$ : Coupling Capacitor, 2000pF

$\mathrm{S}$ : Specimen $\quad \mathrm{R}$ : Shunt resistor, $10 \Omega$ Ar:Neon tube ZNR: Surge absorber $\mathrm{R} 1, \mathrm{R} 2$ : Resistive divider, $1 \mathrm{k} \Omega$

Fig.2 Test circuit for leakage current measurement. 
Table 3 Test conditions.

\begin{tabular}{|c|c|}
\hline Items & Details \\
\hline Insulator & $\begin{array}{l}\text { Pin type } \\
\text { Strain type }\end{array}$ \\
\hline State & $\begin{array}{l}\text { Sound } \\
\text { Cracked in head }\end{array}$ \\
\hline $\begin{array}{l}\text { Applied } \\
\text { voltage }\end{array}$ & $\begin{array}{l}4 \mathrm{kV}, \quad 60 \mathrm{~Hz}, \text { corresponding to } \\
\text { line-to-line voltage of } 6.6 \mathrm{kV}\end{array}$ \\
\hline Environment & $\begin{array}{l}\text { 1. Dry } \\
\text { 2. Wet } \\
\text { 3. Moistened } \\
\text { 4. Spray of } 3 \% \text { salt water } \\
\text { 5. After dipped in tap water } \\
\text { 6. After dipped in salt water } \\
\text { 7. Contamination to } 0.35 \mathrm{mg} / \mathrm{cm}^{2}\end{array}$ \\
\hline $\begin{array}{l}\text { Measuring } \\
\text { freq. band }\end{array}$ & $\mathrm{DC}$ to $100 \mathrm{kHz}$ \\
\hline
\end{tabular}

Table 4 Kinds of training patterns.

\begin{tabular}{|c|c|c|}
\hline State & Pin type & Strain type \\
\hline Sound & $\begin{array}{l}\text { 1. Dry } \\
\text { 2. Wet } \\
\text { 3. Moistened } \\
\text { 4. Spray of } \\
\text { salt water } \\
\text { 5. Contamination } \\
\text { to } 0.35 \mathrm{mg} / \mathrm{cm}^{2}\end{array}$ & $\begin{array}{l}\text { 1. Dry } \\
\text { 2. Wet } \\
\text { 3. Moistened } \\
\text { 4. Spray of } \\
\text { salt water }\end{array}$ \\
\hline $\begin{array}{l}\text { Cracked } \\
\text { in head }\end{array}$ & $\begin{array}{l}\text { 1. Dry } \\
\text { 2. Wet } \\
\text { 3. Moistened } \\
\text { 4. After dipped } \\
\text { in tap water } \\
\text { 5. After dipped } \\
\text { in salt water } \\
\text { 6. Contamination } \\
\text { to } 0.35 \mathrm{mg} / \mathrm{cm}^{2}\end{array}$ & $\begin{array}{l}\text { 1. Dry } \\
\text { 2. Wet } \\
\text { 3. Moistened } \\
\text { 4. After dipped } \\
\text { in tap water } \\
\text { 5. After dipped } \\
\text { in salt water } \\
\text { 6. After dipped in } \\
3 \% \text { salt water }\end{array}$ \\
\hline
\end{tabular}

(1) Under dry condition, there was no significant difference in the magnitude and pattern for the sound and cracked insulators.

(2) When the insulator with a crack in head was moistened, acute points were observed in the leakage current; the magnitude suddenly increased from some ten microamperes to, say, several ten milliamperes.

(3) When insulators were very heavily contaminated, intermittent acute points were observed in the leakage current.

\section{Electrical Insulation Diagnosis using Neural Network Simulation System}

\subsection{Neural Network Simulation System}

A program of neural network simulation system

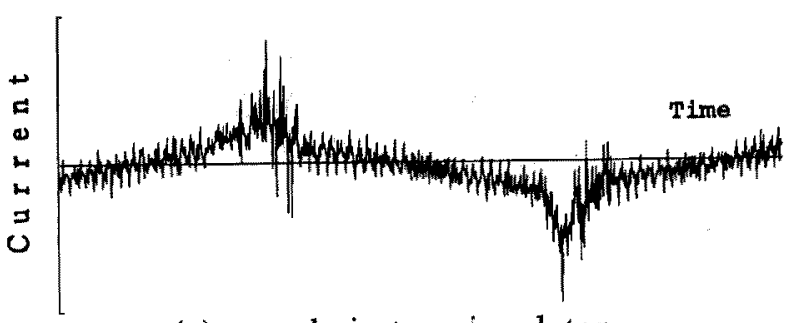

(a) sound pin type insulator, contamination to $0.35 \mathrm{mg} / \mathrm{cm}^{2}$

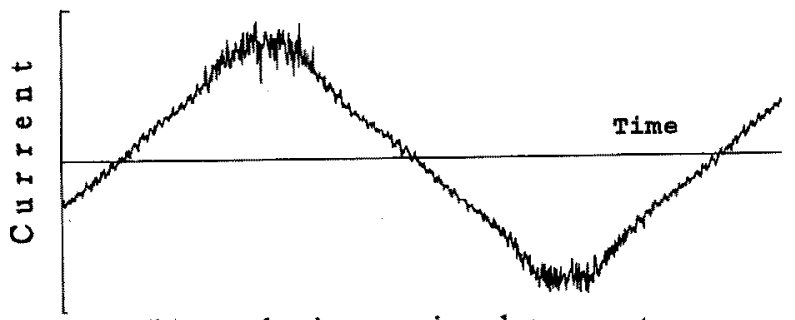

(b) crack pin type insulator, wet

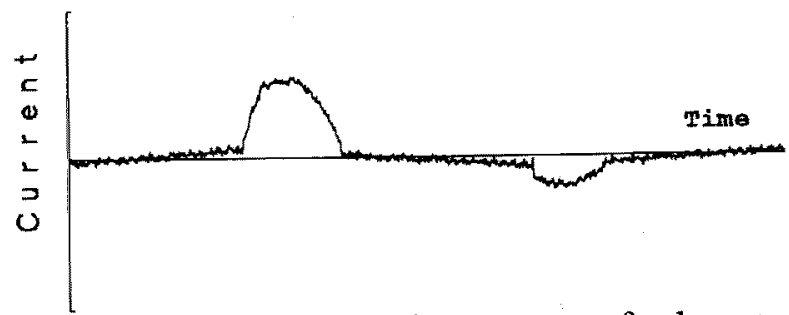

(c) sound strain type insulator, spray of salt water

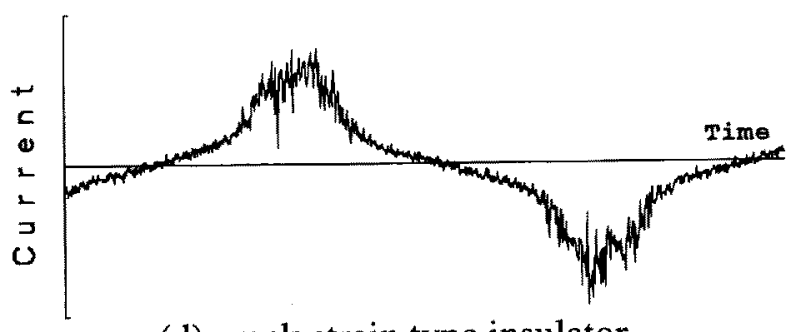

(d) crack strain type insulator, after dipped $3 \%$ salt water

Fig.3 Examples of leakage current waveforms

was constructed on UNIX S-4/IX. This program adopts the so-called layered network with back propagation system in which modification is done every training cycle ${ }^{(4)}$.

Figure 4 shows a schematic description of a layered neural network, which consists of many units named processing elements (PEs). Each PE is connected to other PEs. Input of a PE is expressed as

$$
\mathrm{x}=\sum_{\mathrm{i}} \mathrm{W}_{\mathrm{i}} \mathrm{u}_{\mathrm{i}}
$$

where $u_{i}$ is the output of the $i$-th unit in the previ- 


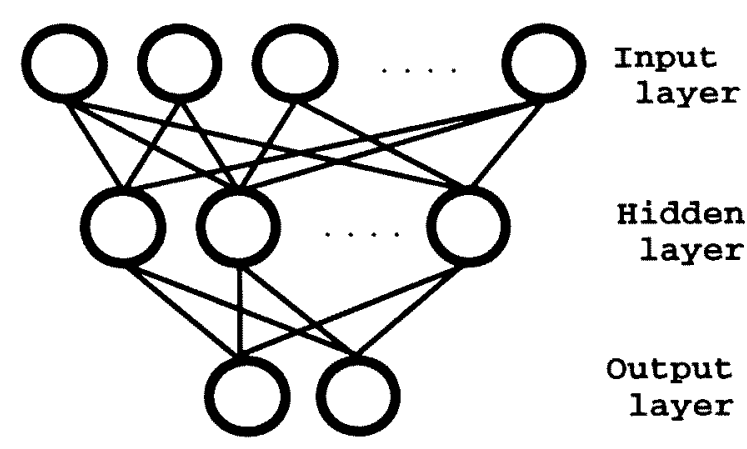

Fig.4 Schematic description of layered neural network.

ous layer and $\mathrm{W}_{\mathrm{i}}$ is the coupling coefficient between the two units. The output $y$ at each unit is expressed as $y=f(x)$, where $f(x)$ is transfer function and $\mathrm{x}$ is input.

The main construction feature of the present neural network simulation system is as follows:

- Number of layers : 3

- Number of units in input layer: 400

( 350 for waveform, 50 for magnitude)

- Number of units in hidden layer: 50

- Number of units in output layer: 2.

It is important in practice to judge if an insulator is sound or not. Thus in the present study, the number of output of this system is two, which express probability of sound and cracked.

Two kinds of transfer functions were used in the present simulation. One is sigmoid function and the other is hyperbolic function, which are expressed as follows, respectively.

$$
\begin{aligned}
& f(x)=\frac{1}{1+\exp (-x)} \\
& f(x)=\tanh (x)
\end{aligned}
$$

Figure 5 shows shapes of the transfer functions.

\subsection{Training Patterns}

Training patterns for the neural network simulation system were produced from typical patterns of the leakage current observed under the surrounding conditions 1-7 in Table 3. Data employed were sampled digital values of leakage currents for each one cycle. At first, electrical insulation diagnosis was tried by using only waveform of leakage current. Here, magnitude of each leakage current waveform was normalized so that

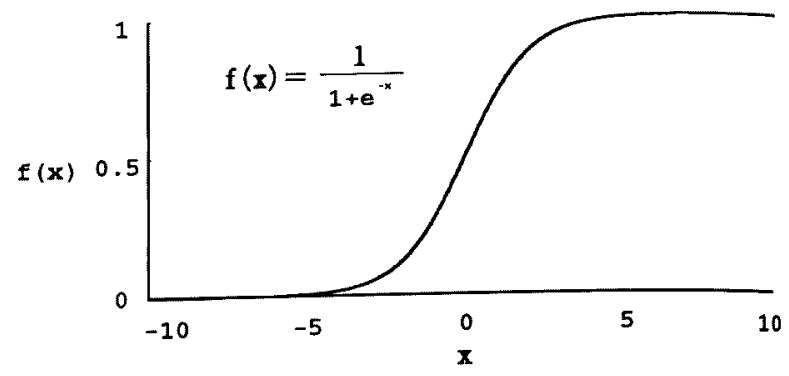

(a)sigmoid function

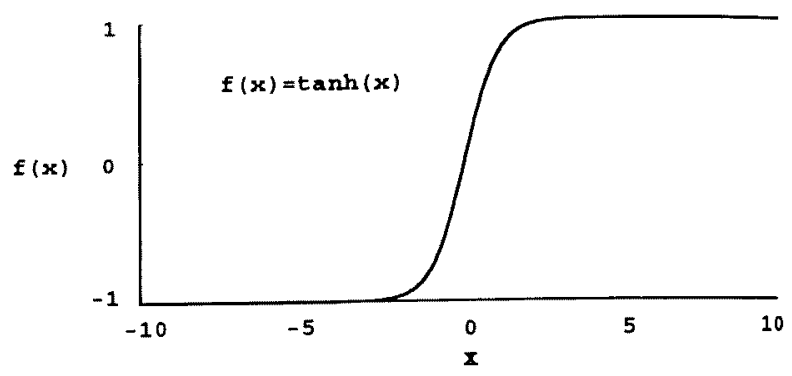

(b)hyperbolic function

Fig.5 Shapes of transfer functions.

the peak current value is unity. This process was made partly because it is difficult to anticipate the maximum magnitude of leakage current obtained in the continuous experiment in the long run. Time axis was divided into 350 parts where corresponding current values were averaged during that part. However, it was proved that simulation results were not necessarily satisfactory when only waveforms of leakage currents were inputted ${ }^{(5)}$. Thus, 50 inputs were allocated to magnitude data of the leakage current because it differs remarkably under various conditions. In the present study, peak value of a current waveform was inputted 50 times to make magnitude data effective.

According to the sampling theorem ${ }^{(6)}$, a signal with the highest frequency component of $\mathrm{W} \mathrm{Hz}$ can be reproduced by using $2 \mathrm{TW}$ data sampled every $1 / 2 \mathrm{~W}$ seconds, where $\mathrm{T}$ is measuring duration. In this study, the highest frequency component of the measured leakage current was $8 \mathrm{kHz}$, which was determined considering background noise and measurement method. The number of division of 350 for one cycle here is enough to characterize the leakage current waveform since it corresponds to the highest frequency component of about $10 \mathrm{kHz}$. The number of training data $\mathrm{em}$ ployed was 5 for each condition shown in Table 3 : thus, 55 and 50 for pin type and strain type insula- 
tors, respectively.

For both insulators under various conditions, the training curve for each waveform was converged in the training cycle of $10,000-20,000$ times.

\subsection{Trial with Arbitrary Data after Training}

Since the training was completed satisfactorily, recognition with high possibility should be possible of arbitrary leakage current obtained in the measurement. Here, several leakage current patterns which were not employed as the training patterns were used as unknown input patterns.

Figures 6 and 7 summarize the simulation results for pin and strain type insulators, respectively. The error was defined as follows: The output of this simulation system denotes the probability of sound and cracked insulators as described in 4.1; When the output is 0.9999 and 0.0001 for sound and cracked states, respectively, for example, the error is $0.01 \%$ if the inputted waveform is obtained on a sound insulator.

The results obtained with smaller number of input unit (120) and that of hidden unit (30) are also shown, where the transfer function is sigmoid.

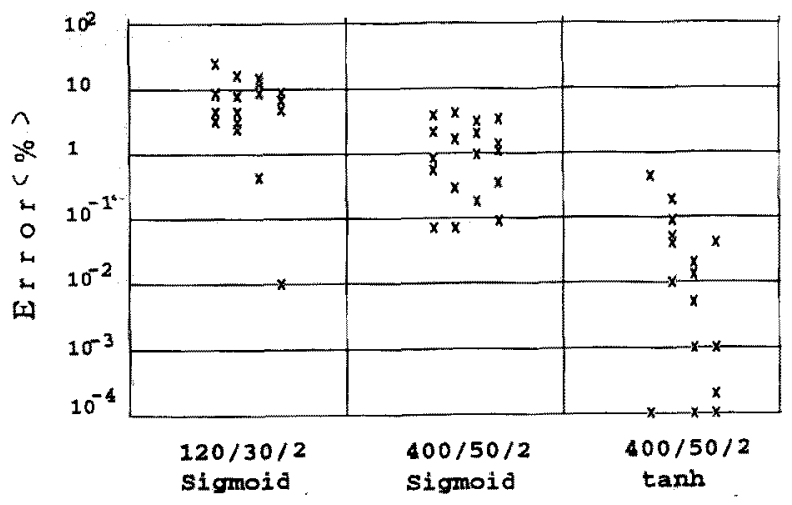

Fig.6 Simulation results for pin type insulator.

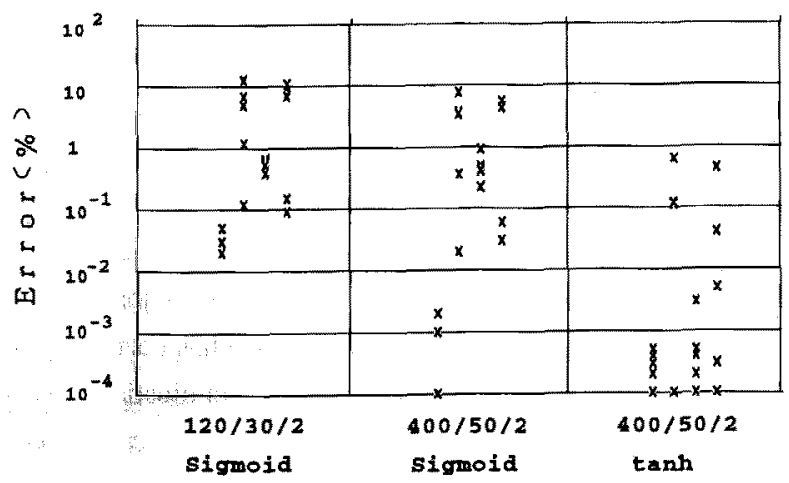

Fig.7 Simulation results for strain type insulator.
Table 5 Simulation results for data in frequency domain.

\begin{tabular}{|c|c|c|}
\hline \multirow{2}{*}{ Waveform \# } & \multicolumn{2}{|c|}{ Error $(\%)$} \\
\cline { 2 - 3 } & Time domain & Frequency domain \\
\hline 1 & 0.24 & 51.3 \\
\hline 2 & 0.17 & 51.3 \\
\hline 3 & 0.16 & 50.6 \\
\hline 4 & 0.39 & 49.2 \\
\hline 5 & 0.22 & 51.1 \\
\hline
\end{tabular}

In this case, poor results were obtained because the leakage current waveform could not be reproduced precisely due to insufficient number of sampling. As shown in the figures, increase of the number of input and hidden units improves simulation results.

In the case of pin type insulators, the maximum error is about $4 \%$ when sigmoid function is used as the transfer function. Usage of hyperbolic function $(\tanh \mathrm{x})$ results in much smaller error of about $0.5 \%$, meaning quite high reliability of judgment. For strain type insulators, the similar tendency is obtained. The advantage of usage of hyperbolic function may be attributed to the sharp change in its value around $x=0$.

Frequency spectra obtained from the leakage current waveforms in the time domain by Fourier transformation, were also used for the insulation diagnosis using the same neural network simulation system. The typical results are shown in Table 5. Magnitude of leakage current waveform is considered in this simulation. Since the number of units in the input layer is not as large as that in the time domain, comparison of the two cases may not be quite fair. Even if taking this situation into account, poor results seem to be obtained in the frequency domain. It may be attributed to little difference among frequency spectra under various conditions and lack of information on phase angle.

A program of neural network simulation system was also made up by using C-Language for use on a machine with CPU of 80486 . This program uses the so-called layered network with back propagation system in which modification is done every training cycle. There is a clear limit in the personal computer in its speed of computation, size of memory, and so on, but it was confirmed that the 
neural network simulation system could give correct recognition for most of the arbitrary input data.

The degradation in the insulation of distribution line insulator, single or plural, will produce leakage current of many different waveform patterns under various condition of rain, contamination, high humidity, etc. With the accumulation of such data in parallel, the authors would like to improve the neural network simulation system developed this time.

\section{Conclusions}

The neural network simulation system was developed to diagnose the electrical insulation capability of distribution line insulators by means of leakage current waveform along the surface of or through the insulators. The results obtained are summarized as follows.

(1) The system gave correct recognition of all the arbitrary input data, which may be attributed to consideration of magnitude as well as waveform of leakage current.

(2) Usage of hyperbolic function ( $\tanh x$ ) as the transfer function led to excellent simulation results compared with that of sigmoid function.

(3) Leakage current waveform in the time domain seems suitable for electrical insulation diagnosis of distribution line insulators compared with spectra in the frequency domain.

The authors thank to Mr.A.Kosugi, Mr.Y.Ando and Mr.S.Matsuura for their assistance in carrying out simulation.

(Manuscript received Oct. 27, 1995; revised Jan. 25, 1996)

\section{References}

(1) H.Mayors et al.: "Application of neural networks to partial discharge pattern recognition", CIGRE SC33 Leningrad Colloquium Paper, No.SC33.91(Coll)1.7-IWD, (1991).

(2) T.Kikuchi et al.: "Development of a Remote Sensing System for Faulty Suspension Insulators", 26th Symposium on Electrical Insulating Materials, JC2-8, Osaka, Japan (1994).

(3) K.Naito et al.: "Faulty Insulator Detector for Transmission Line", NGK Review, No.44, pp.11-25 (1983), in Japanese.

(4) K.Nakano: "Neurocomputer", Gijutsu-Hyoron sha, (1988), in Japanese.

(5) Y.Ando et al.: "Application of neural network simulation system to diagnosis of power distribution equipment", Annual meeting of Tokai Branch, JEE, No.72 (1993).
(6) N.Honda: "Introduction to information theory", Nikkan Kogyo Shimbunsha, (1973), in Japanese.

Yukio MIZUNO (Member) He was born in 1958. He

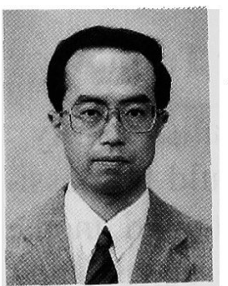
received the B.S., M.S. and Ph.D. degrees, all in electrical engineering from Nagoya University in 1981, 1983 and 1986, respectively. From 1986 to 1993, he was employed as a research associate at Toyohashi University of Technology. In 1993 he joined Nagoya Institute of Technology as an associate professor of Department of Electrical and Computer Engineering. $\mathrm{He}$ is a member of Cryogenic Association of Japan and IEEE.

Oscar F. VANEGAS C. (Non-member) He was born in

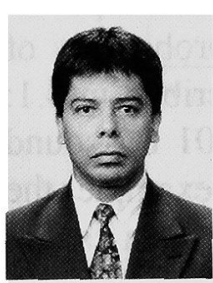
Santafe de Bogota, Colombia in 1960. He received the B.S. degree from the National University of Colombia. He studied in M.S. course in Artificial Intelligence at the same university. From 1995, he is studying towards M.S. degree in Electrical and Computer Engineering at Nagoya Institute of Technology.

Katsuhiko NAITO (Member) He was born in 1934. He received the B.S., M.S. and Ph.D. degrees, all
in electrical engineering from Nagoya Univer-
sity in 1958, 1960 and 1976, respectively. In
1960 he joined NGK Insulators. Ltd. He
served as General Manager of NGK HV
Laboratory and recently as Executive Chief Engineer of Power Business Group of the company. In 1991 he left the company and joined Nagoya Institute of Technology as a full Professor of the Electrical and Computer Engineering Department. He is a Fellow of IEEE and a member of CIGRE.

Tsutomu SUGIYAMA (Non-member) He was born in

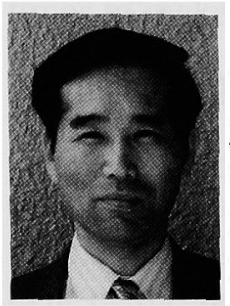
1947. He was graduated from Higashiyama Technical High School in 1966. In 1966 he joined NGK INSULATORS, LTD. He has been engaged in high voltage test of insulators. $\mathrm{He}$ is now working in NGK High Voltage Laboratory, Power Business Group.

Susumu ITO (Member) He was born in 1948. He was

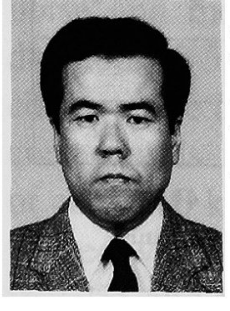
graduated from Suzuka National College of Technology in 1969. In 1969 he joined NGK INSULATORS, LTD. He has been engaged in corona, dielectric and contamination tests of insulators. He is now a Manager of NGK High Voltage Laboratory, Power Business Group. 